\title{
Influence of Control Parameters in VOCs Evolution during MSW Trimming Residues Composting
}

\author{
Margarita Delgado-Rodríguez, ${ }^{\dagger}$ Mercedes Ruiz-Montoya, ${ }^{\dagger}$ Inmaculada Giraldez, ${ }^{\ddagger}$ Rafael López, ${ }^{\S}$ \\ Engracia Madejón, ${ }^{\S}$ and Manuel Jesús Díaz ${ }^{*,+}$ \\ ${ }^{\dagger}$ Departamento de Ingeniería Química, Química Física y Química Orgánica and ${ }^{\ddagger}$ Departamento de Química, \\ Facultad de Ciencias Experimentales, Campus de "El Carmen", Universidad de Huelva, 21071, Huelva, Spain \\ ${ }^{\S}$ Instituto de Recursos Naturales y Agrobiología de Sevilla, IRNAS-CSIC, Avda. Reina Mercedes 10, 41012, Sevilla, Spain
}

ABSTRACT: The influence of control parameters (aeration, moisture, and $\mathrm{C} / \mathrm{N}$ ratio) during composting of a municipal solid waste (MSW)-legume-trimming residue (LTR) mixture was studied at a pilot plant scale. Factors measured included the composition of the main volatile organic carbons (VOCs) emitted including limonene, $\beta$-pinene, 2 -butanone, undecane, phenol, toluene, and dimethyl disulfide. Polynomial models were found to reproduce the experimental results with errors at less than $10 \%$. The relative influence of the independent variables on temperature and selected VOCs followed the order: aeration $>$ moisture $>\mathrm{C} / \mathrm{N}$. A high aeration rate results in higher (strong negative effect) values on selected VOCs emissions (41-71\% on emitted VOCs variation). Moisture had a positive and negative effect depending on the selected VOCs. A high $\mathrm{C} / \mathrm{N}$ ratio caused lower production of VOCs except for undecane and 2-butanone. Providing an aerobic environment ( $\left.0.05 \mathrm{Lair} \mathrm{kg}^{-1} \mathrm{~min}^{-1}\right)$, high C/N ratios $(>50)$, and medium moisture (55\%) minimize emitted VOCs during MSW composting, ultimately resulting in less odors in the surrounding environment.

KEYWORDS: VOCs, MSW, composting, limonene, 2-butanone

\section{INTRODUCTION}

There is an ever increasing interest in the use of composting technology to provide an ecologically sound and cost-effective solution to the management of municipal solid waste (MSW). ${ }^{1}$ Composting is the biological decomposition of organic matter under controlled aerobic conditions. The objectives of composting are to reduce pathogens to below detectable levels, degrade volatile solids, and produce a usable product.

Currently, composting facilities are considered to be a great source of unpleasant odors. Moreover, they attract additional traffic that results in additional noise, dust, and congestion. ${ }^{2}$ Odors have also always been considered an uncomfortable nuisance for the workers of the composting facilities. Compost production has traditionally been carried out in remote areas that rarely affected the human population. In recent years, the increase in urbanization of cities has brought many composting plants closer to urban cores. Odor is becoming a serious point of conflict between composters and their neighbors. Odor control is often the most significant problem that composting facilities have to face, and it is often the biggest hurdle toward gaining public acceptance of a facility. Finding a solution is vital to the economy, since waste disposal is an essential service that affects both business and the environment. ${ }^{3}$

Volatile organic compounds (VOCs) produced during composting are responsible for part of the unpleasant odors. They can have xenobiotic origins (e.g., aromatic hydrocarbons), due to the presence of hazardous household wastes in the composted mixtures. ${ }^{4}$

According to previous studies, hundreds of VOCs are emitted during the biodegradation process of municipal waste organic fraction in composting plants. ${ }^{5}$ These VOCs can be arranged in common chemical classes: aromatics, ketones, hydrocarbons, terpenes, alcohols, and volatile fatty acids. Many techniques for quantifying the most significant components, and compounds of compost odors are being developed. ${ }^{4,6}$ Malodorous components generally contain nitrogen (mainly $\mathrm{NH}_{3}$ ) or sulfur (mainly $\mathrm{SH}_{2}$ ), amines, phenolic compounds, aldehydes, thiols, ketones, and alcohols. ${ }^{7}$ Each of these components is primarily formed through the activity of microorganisms that degrade the complex organic compounds present in the organic matter. Mao et al. ${ }^{8}$ and Tsai et al. ${ }^{9}$ identified six critical odorant compounds in MSW degradation.

Odor problems can be reduced by preventing the generation of these compounds, diluting them, or treating the air to reduce their offensiveness. Before addressing techniques for reducing atmospheric emission, the factors that have the greatest impact on VOCs generation must be investigated, and then, through proper management, odors can be prevented and minimized. The dependence of odors or VOCs on the composting system and certain composting parameters has been studied; ${ }^{10,11}$ however, minimal bibliographic data have been found on the influence of composting parameters on the evolution of certain VOCs emitted in the composting process.

A successful composting plant design is based on the optimization of the composting parameters (aeration, particle size, C/ $\mathrm{N}$, moisture, initial $\mathrm{pH}$, etc.) and minimization of VOCs emission. The aim of this study was to elucidate the optimum values, at pilot plant scale, for aeration, moisture, and $\mathrm{C} / \mathrm{N}$ ratios in MSW composting to minimize VOC emissions.

Received: September 6, 2011

Accepted: November 7, 2011

Revised: November 6, 2011

Published: November 07, 2011 
Table 1. Relevant Characteristics of Feedstocks ${ }^{a}$ Used in Composting Reactors to Determine the Effect of Various Control Parameters

\begin{tabular}{|c|c|c|c|}
\hline & & MSW & LTR \\
\hline $\mathrm{pH}(1: 5$ extract $)$ & & $5.95 \pm 0.2$ & $6.93 \pm 0.1$ \\
\hline EC (1:5 extract) & $\mathrm{dS} \mathrm{m}^{-1}$ & $8.29 \pm 0.1$ & $2.12 \pm 0.1$ \\
\hline organic matter & $\mathrm{g} \mathrm{kg}^{-1}$ & $690.6 \pm 8.3$ & $790.3 \pm 5.6$ \\
\hline Kjeldahl-N ${ }^{2}$ & $\mathrm{~g} \mathrm{~kg}^{-1}$ & $21.29 \pm 1.0$ & $3.24 \pm 0.2$ \\
\hline $\mathrm{C} / \mathrm{N}$ & & $17.1 \pm 3.1$ & $128.4 \pm 10.8$ \\
\hline bulk density & $\mathrm{g} \mathrm{L}^{-1}$ & $290.6 \pm 33.5$ & $92.4 \pm 13.2$ \\
\hline \multicolumn{4}{|c|}{ particle size } \\
\hline$>25 \mathrm{~mm}$ & $\%$ & $47.55 \pm 6.0$ & \\
\hline $25-10 \mathrm{~mm}$ & $\%$ & $28.38 \pm 2.9$ & \\
\hline $10-5 \mathrm{~mm}$ & $\%$ & $13.13 \pm 2.2$ & \\
\hline $5-2 \mathrm{~mm}$ & $\%$ & $7.04 \pm 0.8$ & \\
\hline$<2 \mathrm{~mm}$ & $\%$ & $3.90 \pm 0.1$ & \\
\hline impurities $>2 \mathrm{~mm}$ & $\%$ & $31.56 \pm 3.6$ & \\
\hline
\end{tabular}

\section{EXPERIMENTAL SECTION}

Materials. MSW was collected from a Córdobás (Spain) urban waste treatment plant. This plant processes the organic fraction of selectively collected urban waste. Pruning waste (legume-trimming residues, LTR) was collected on Campus La Rábida (Huelva University, Palos de la Frontera, Spain) and was mixed to get uniform feed material and chipped $(2-3 \mathrm{~cm})$ in situ. Relevant characteristics of MSW and LTR are given in Table 1.

Composting Reactors. A total of 16 composting reactors have been required to perform the study. Each one of the composting reactors (PE) was airtight, with a small gas exit hole, $0.5 \mathrm{~cm}$ in diameter, and acrylic barrels with a capacity of $200 \mathrm{~L}$. To minimize the conductive heat loss along the reactor wall, they were insulated with polyurethane foam. To ensure the initial moisture conditions in reactors, water losses, after opening the top cover, were compensated by adding water during active composting.

Two temperature sensors ( $\mathrm{K}$ thermocouples, TMC6-HA) were placed at the center and the top of the composting mass. An additional temperature sensor was placed outside the reactors to obtain the environmental temperature (Protimeter-MMS-Plus). Temperatures were recorded every $12 \mathrm{~h}$ in each reactor by two data loggers (HOBO, U12-006). Compressed air (at different rates following the experimental design $0.005-0.300 \mathrm{~L}_{\mathrm{air}} \mathrm{kg}^{-1} \mathrm{~min}^{-1}$ : dry weight basis) was introduced into the bottom of each reactor and was evenly distributed to the composting mixture through a perforated plate.

Chemical Analytical Methods. Feedstock MSW and LTR samples were obtained before the start of the experiment. In MSW, particle size distribution was determined by a sieve shaker, and impurities (glass, plastics, metals, and stones) were hand separated and weighed. In the case of LTR, the particle size determination was not possible due to its fibrous character. The total organic matter was determined by the weight loss after dry combustion at $540{ }^{\circ} \mathrm{C}$, and organic carbon was estimated by multiplying organic matter by $0.58 .^{12}$ Nitrogen $(\mathrm{N})$ was determined by steam distillation after Kjeldahl digestion. ${ }^{13}$ In the case of MSW, organic matter and nitrogen determinations were done in the $<5 \mathrm{~mm}$ size fraction. The analyses were carried out in triplicate.

The moisture in the compost samples was quickly determined by an Infrared Moisture Analyzer (COBOS IB110) to correct moisture loss in the reactors by adding water to get the moisture content to the starting point in the experimental design (section 2.5). The $\mathrm{pH}$ was determined in a 1:5 ratio (in weight) compost:water extracts using a $\mathrm{pH}$ electrode.

Air samples for each reactor (two randomized points and mixed) were taken according to the rate of the composting process at $0,2,6,14,21$, and 36 days from the start of the experiment. The gas mass flow rate (in and out) has been directly measured by a primary standard gas flow meter in each reactor.

Air Sampling and Analysis Procedure. Air samples for the VOC compounds determination were collected in every reactor (duplicate samples were taken at each sampling time) in Tedlar bags (Supelco, Bellefonte, PA) with a vacuum pump (KNF Micro Diaphragm Pump) and were transported to the laboratory for analysis. The samples were taken from the headspace of the reactor with no alteration in the air flow of the composting reactor. Waste air headspace $(0.35 \mathrm{~m})$ was left for the purpose of air sampling in reactors during the original setup. The sample flow rate and volume were $31 \mathrm{~mL} \mathrm{~s}^{-1}$ and $1-2 \mathrm{~L}$, respectively. The flow rate vacuum pump was checked occasionally using a primary standard (soap-blue meter). Air samples were preserved at $4{ }^{\circ} \mathrm{C}$, protected from light exposure, and analyzed within $24 \mathrm{~h}$.

VOC compounds were concentrated using a solid-phase microextraction (SPME) method. A SPME fiber, coated with $75 \mu \mathrm{m}$ carboxenpolydimethylsiloxane (Supelco), was employed to maximize the efficiency in VOCs capture ${ }^{14-16}$ compounds in Tedlar bags. The SPME fiber was manually inserted into the bag for $30 \mathrm{~min}$. The SPME fiber coating containing volatile compounds was inserted into the GC injection port at $230{ }^{\circ} \mathrm{C}$ where it remained for $3 \mathrm{~min}$ for the analysis of volatile compounds. After each sample injection, fibers were kept inside the SPME needle to prevent possible contamination and were conditioned with helium at $250{ }^{\circ} \mathrm{C}$ for $10 \mathrm{~min}$ before reuse.

The desorption of volatile compounds was performed using an Agilent 6890 gas chromatograph system, coupled to a quadrupole Agilent 5973 electron ionization $(70 \mathrm{eV})$ mass spectrometric detector (Agilent Technologies, Palo Alto, CA) equipped with an Agilent HP5MS fused silica capillary column $(30 \mathrm{~m} \times 0.25 \mathrm{~mm}$ i.d., $0.25 \mu \mathrm{m}$ film thickness). The GC was equipped with a split/splitless injection port operating in splitless mode. The oven temperature was programmed from $40(5 \mathrm{~min})$ to $270{ }^{\circ} \mathrm{C}(20 \mathrm{~min})$ by increasing the temperature at $5{ }^{\circ} \mathrm{C} \mathrm{min}{ }^{-1}$. The transfer line was heated at $280^{\circ} \mathrm{C}$. The carrier gas was helium with a constant flow of $1 \mathrm{~mL} \mathrm{~min}^{-1}$ (mean velocity $36 \mathrm{~cm} \mathrm{~s}^{-1}$ ). The mass spectrometer was operated in scan mode $(35-550 \mathrm{amu})$. Identification of volatile compounds was achieved by comparing the GC retention times and mass spectra with those, when available, of the pure standard compounds. All mass spectra were also compared with the data system library (NIST 98). Quantification of samples was conducted by the external standard method following the same sampling procedure as that for on-site samples. After sample quantification, depending on the total mass in the reactor and the outflow, its equivalence to $\mathrm{mg} \mathrm{kg}^{-1}$ days $^{-1}$ has been calculated.

Experimental Design and Statistical Analysis. To be able to relate the dependent (temperature and VOCs) and independent variables (moisture, aeration, and $\mathrm{C} / \mathrm{N}$ ) with the minimum possible number of experiments, an orthogonal main effect design consisted of a central one point (central experiment, in the center of a cube, duplicated), and 14 additional points (additional experiments lying at the cube vertices) were used (Box-Wilson Central Composite Design ${ }^{17}$ ). This experimental design (Table 2) enabled the construction of first-order polynomials in the independent variables, and the identification of statistical significance in the variables was used. The polynomial model used was of the following type:

$$
Z=a_{0}+\sum_{i=1}^{n} b_{i} X_{n i}+\sum_{i=1 ; j=1}^{n} d_{i} X_{n i} X_{n j}(i<j)
$$

where $Z$ and $X_{n i}$ denote dependent and normalized independent variables, respectively, and $a_{0}, b_{i}, c_{i}$, and $d_{i j}$ are unknown constants obtained from 
Table 2. Treatments Associated with Various Reactors for Development of Factorial Design for Determination of Effects of Control Parameters

\begin{tabular}{|c|c|c|c|c|c|}
\hline reactor & $\begin{array}{l}\text { MSW:LTR } \\
(w: w) \text { ratio }\end{array}$ & $\mathrm{C} / \mathrm{N}$ & $\begin{array}{c}\text { aeration } \\
L_{\text {air }} \mathrm{kg}^{-1} \min ^{-1}\end{array}$ & moisture \% & $\mathrm{C} / \mathrm{N}, \mathrm{A}, \mathrm{M}^{a}$ \\
\hline 1 & $1: 2$ & 77 & 0.300 & 70 & $+1,+1,+1$ \\
\hline 2 & $1: 0$ & 21 & 0.300 & 70 & $-1,+1,+1$ \\
\hline 3 & $1: 2$ & 77 & 0.300 & 40 & $+1,+1,-1$ \\
\hline 4 & $1: 0$ & 21 & 0.300 & 40 & $-1,+1,-1$ \\
\hline 5 & $1: 2$ & 77 & 0.050 & 70 & $+1,-1,+1$ \\
\hline 6 & $1: 0$ & 21 & 0.050 & 70 & $-1,-1,+1$ \\
\hline 7 & $1: 2$ & 77 & 0.050 & 40 & $+1,-1,-1$ \\
\hline 8 & $1: 0$ & 21 & 0.050 & 40 & $-1,-1,-1$ \\
\hline 9 & $1: 1$ & 60 & 0.300 & 55 & $0,+1,0$ \\
\hline 10 & $1: 1$ & 60 & 0.050 & 55 & $0,-1,0$ \\
\hline 11 & $1: 1$ & 60 & 0.175 & 70 & $0,0,+1$ \\
\hline 12 & $1: 1$ & 60 & 0.175 & 40 & $0,0,-1$ \\
\hline 13 & $1: 2$ & 77 & 0.175 & 55 & $+1,0,0$ \\
\hline 14 & $1: 0$ & 21 & 0.175 & 55 & $-1,0,0$ \\
\hline 15 & $1: 1$ & 60 & 0.175 & 55 & $0,0,0$ \\
\hline 16 & $1: 1$ & 60 & 0.175 & 55 & $0,0,0$ \\
\hline
\end{tabular}

${ }^{a}$ Normalized values for $\mathrm{C} / \mathrm{N}(\mathrm{C} / \mathrm{N})$, aeration $(\mathrm{A})$, and moisture $(\mathrm{M})$, respectively.

experimental data. Independent variables were normalized $\left(X_{n}\right)$ by using the following equation:

$$
X_{n}=\left(X-X_{\operatorname{med}}\right) /\left[\left(X_{\max }-X_{\min }\right) / 2\right]
$$

where $X$ is the absolute value of the independent variable concerned, $X_{\text {med }}$ is the average value of the variable, and $X_{\max }$ and $X_{\min }$ are their maximum and minimum values, respectively.

The independent variables used in the equations relating to both types of variables were those having a statistically significant coefficient (viz. those not exceeding a significance level of 0.05 in Student's $t$ test and having a $95 \%$ confidence interval excluding zero).

At this point, the $\mathrm{C} / \mathrm{N}$ ratio used (assuming that the entire $\mathrm{N}$ is biodegradable) is, approximately, a chemical $\mathrm{C} / \mathrm{N}$, and a fraction of the carbon may be unavailable for microorganisms. The moisture, aeration, and $\mathrm{C} / \mathrm{N}$ used in the factorial design (Table 2 ) were 40,55 , and $70 \%$ for moisture, ${ }^{18} 0.05,0.175$, and $0.300 \mathrm{~L}_{\text {air }} \mathrm{kg}^{-1} \mathrm{~min}^{-1}$ (dry matter basis) for aeration, ${ }^{19}$ and 21,60 , and 77 for $\mathrm{C} / \mathrm{N}^{20}{ }^{20}$ Thus, the extreme values for each independent variable shall be defined as low $(-1)$ and high levels $(+1)$. The central combination for the experimental design $(0,0,0$; duplicated) was as follows: aeration, $0.175 \mathrm{~L}_{\text {air }} \mathrm{kg}^{-1} \mathrm{~min}^{-1}$; moisture, $55 \%$; and $\mathrm{C} / \mathrm{N}, 60$. The composting time was considered as an independent variable in the model. Temperature and VOCs were considered as dependent variables.

Following the experimental design proposed, MSW and LTR were mixed in three different MSW:LTR dry mass ratios: 1 (MSW):0 (LTR), $1: 1$, and $1: 2$ to obtain three different values for the $\mathrm{C} / \mathrm{N}(21,60,77)$ ratio in the mixtures. Water was added to obtain one of three levels of moisture: 40,55 , or $70 \%$. Each mixture was then transferred to the composting reactor following the experimental design indicated below, half filling the reactor ( $40 \mathrm{~kg}$ per reactor) to permit air exchange. The experiment and experimental design were set up at the same time. The MATLAB (Release 2006a) statistical package was used for all analyses.

Main VOCS Emitted in MSW Composting Plants. Mainly, $\mathrm{H}_{3} \mathrm{~N}, \mathrm{H}_{2} \mathrm{~S}$, and VOCs emitted are responsible for odor problems common to composting operations. High $\mathrm{NH}_{3}$ emissions for wastes with high initial $\mathrm{N}$ content are reported. ${ }^{3,21}$ The $\mathrm{NH}_{3}$ evolution during
Table 3. Common VOC Compounds Previously Identified in MSW Composting along with the Detection in This Study

\begin{tabular}{lll}
\multicolumn{1}{c}{ VOC } & \multicolumn{1}{c}{ refs } & found in this study \\
acetic acid & $7,9,25$ & yes \\
acetone & $8,9,25,26$ & no \\
benzene & $8,914,26,27,29$ & yes \\
butanol & $25,28,29$ & no \\
butanone & $8,9,25,26,28-30$ & yes \\
carene & $8,25,26$ & yes \\
decane & $14,27,29,31$ & yes \\
dodecane & $14,29,31$ & yes \\
ethyl-acetate & $25,28,29$ & no \\
ethyl-benzene & $4,8,9,14,26,27,29,31$ & yes \\
hexenes & $8,9,27$ & no \\
isopropyl-benzene & $4,26,29$ & no \\
limonene & $7-9,14,25,26,28-31$ & yes \\
methyl-sulfides & $7,9,30$ & yes \\
methyl-benzenes & $14,26,27,31$ & no \\
naphthalene & $4,14,26,27$ & no \\
octane & $14,27,29,31$ & yes \\
pentenes & $4,9,27$ & no \\
pinenes $(\alpha, \beta)$ & $8,9,14,25,27-31$ & yes \\
propyl-benzenes & $4,14,26,27$ & no \\
styrene & $4,89,26,29$ & no \\
tetrachloroethene & $14,26,27,30,31$ & no \\
toluene & $7,9,14,25-27,29,31$ & yes \\
undecane & $14,29,31$ & yes \\
xylenes & $4,8,9,14,25-27,29,31$ & yes \\
\hline
\end{tabular}

composting depends on the temperature, oxygenation rate, and $\mathrm{C} / \mathrm{N}$ ratio. ${ }^{21,22}$ For $\mathrm{H}_{2} \mathrm{~S}$, anaerobic conditions favor the formation of volatile sulfur compounds. Consequently, a high aeration strongly reduced its production. ${ }^{23}$ According to previous studies, hundreds of VOCs are emitted during the biodegradation process of municipal waste organic fraction in composting plants. ${ }^{24}$ Moreover, Mao et al. ${ }^{8}$ and Tsai et al. ${ }^{9}$ found six critical odorants in MSW degradation (ethylbenzene, dimethylsulfide, trimethylamine, cymene, ammonia, and acetic acid). Most of the common compounds emitted during the MSW composting process ${ }^{4,9,25}$ have been detected in the present experiment, although some of these critical compounds have not been observed (Table 3). In this sense, most of the compounds that have not been found are mainly attributed to the low presence of polymer components such as plastics (benzene derivates), rubber (styrene), and other liquid oils (linear hydrocarbons, naphthalene). Among the compounds found, seven VOCs were targeted for further quantification in this study. These VOCs were selected because of their availability and high concentration in our conditions. They are also representatives of the most important classes of compounds with high odor impact. ${ }^{30}$ The selected VOCs were as follows: limonene (CAS no. 95327-98-3), $\beta$-pinene (CAS no. 80-56-8), 2-butanone (CAS no. 78-93-3), undecane (CAS no. 61193-21-3), phenol (CAS no. 8002-07-1), toluene (CAS no. 50646-98-5), and dimethyl disulfide (CAS no. 68920-64-9). The presence of terpenes in MSW can be explained as products of vegetable matter biodegradation. Alkanes and aromatics were detected in unseeded mixed paper with food wastes. ${ }^{4}$ Sulfides could be a result of anaerobic biological decomposition. These compounds were modeled to evaluate the relative influence of variables on the evolution of these compounds in the composting process. 
Table 4. Equations Yielded for Each Dependent ${ }^{a}$ Variable $\left({ }^{\circ} \mathrm{C} \text { for Temperature and } \mathrm{mg} \mathrm{kg}^{-1} \mathrm{days}^{-1} \text { for VOCs }\right)^{b}$

\begin{tabular}{|c|c|c|c|}
\hline compds & $r^{2 c}$ & $F^{c}$ & $\mathrm{df}^{c}$ \\
\hline$T=39.01-18.18 t+5.34 t^{2}-2.81 \mathrm{cn}^{2}-4.41 \mathrm{ta}-2.09 \mathrm{tm}-2.85 \mathrm{am}$ & 0.75 & 7.7 & 14.5 \\
\hline $\mathrm{LI}=0.00559-0.006133 t+0.00186 t^{2}-0.000906 \mathrm{~m}^{2}+0.00085 \mathrm{tm}-0.00063 \mathrm{am}$ & 0.92 & 49.5 & 14.5 \\
\hline $\mathrm{BP}=0.000870-0.00589 t+0.005871 t^{2}+0.0009883 t m$ & 0.82 & 19.2 & 14.5 \\
\hline $2 \mathrm{~B}=-0.00023-0.00503 t-0.00044 \mathrm{cn}+0.00625 t^{2}+0.00065 \mathrm{~m}^{2}+0.00176 \mathrm{~cm}+0.00098 \mathrm{ta}+0.000519 \mathrm{ca}+0.00088 \mathrm{am}$ & 0.94 & 68.2 & 14.6 \\
\hline $\mathrm{UN}=0.00070-000.020 t+0.00032 t^{2}+0.00004 t m-0.000028 \mathrm{am}$ & 0.77 & 8.5 & 14.5 \\
\hline $\mathrm{PH}=0.00049-0.00031 t+0.00006 \mathrm{cn}-0.00006 \mathrm{~m}+0.00027 t^{2}+0.00008 \mathrm{ta}+0.00009 \mathrm{tm}-0.00012 \mathrm{am}$ & 0.78 & 16.4 & 14.5 \\
\hline $\mathrm{TO}=0.00194-0.00071 t+0.00037 a+0.00024 m-0.00113 t^{2}+0.00051 m^{2}$ & 0.78 & 9.7 & 14.5 \\
\hline $\mathrm{DDS}=0.00088-0.005511 t-0.00036 a+0.00044 m^{2}$ & 0.76 & 8.9 & 14.6 \\
\hline
\end{tabular}

${ }^{a}$ Each value is the average of three samples on a dry weight basis. Percentages with respect to organic matter content. ${ }^{b}$ Where $t, a, m$, and cn denote the normalized value of the operation time, aeration, moisture, and $\mathrm{C} / \mathrm{N}$ ratio, respectively, as independent variables. In addition, $T=$ temperature, $\mathrm{LI}=$ limonene, $\mathrm{BP}=\beta$-pinene, $\mathrm{B}=2$-butanone, $\mathrm{UN}=$ undecane, $\mathrm{PH}=$ phenol, $\mathrm{TO}=$ toluene, and $\mathrm{DDS}=$ dimethyl-disulfide as dependent variables. ${ }^{c}{ }^{2}{ }^{2}, \mathrm{~F}$, and $\mathrm{df}$ denote the coefficient of determination, Fisher-Snedecor distribution, and degrees of freedom, respectively. The differences between the experimental values and those estimated by using the previous equations never exceeded $10-15 \%$ of the former.

\begin{tabular}{|c|c|c|c|}
\hline \multirow[b]{2}{*}{$\begin{array}{l}\text { Dependent variables } \\
\text { (highest and lowest values) }\end{array}$} & \multicolumn{3}{|c|}{$\begin{array}{l}\text { Independent variables } \\
\text { (Relative influence \%) }\end{array}$} \\
\hline & $\begin{array}{c}\text { Aeration } \\
(-1,1)\end{array}$ & $\begin{array}{c}\text { Moisture } \\
(-1,1)\end{array}$ & $\begin{array}{c}\mathrm{C} / \mathrm{N} \\
(-1,1)\end{array}$ \\
\hline \multicolumn{4}{|l|}{$\begin{array}{c}\text { Temperature }\left({ }^{\circ} \mathrm{C}\right) \\
(28.2-71.6)\end{array}$} \\
\hline & $(34.5 \%)$ & $(24.4 \%)$ & $(12.4 \%)$ \\
\hline \multicolumn{4}{|l|}{$\begin{array}{l}\text { Limonene } \\
\left(\mathrm{mg} \mathrm{kg}^{-1} \mathrm{~d}^{-1}\right) \\
(0-0.03)\end{array}$} \\
\hline & (49.6\%) & $(24.7 \%)$ & $(6.4 \%)$ \\
\hline \multicolumn{4}{|l|}{$\begin{array}{c}\beta \text {-pinene } \\
\left(\mathrm{mg} \mathrm{kg}^{-1} \mathrm{~d}^{-1}\right) \\
(0-0.025)\end{array}$} \\
\hline \multicolumn{4}{|l|}{$\begin{array}{c}\text { 2-butanone } \\
\left(\mathrm{mg} \mathrm{kg}^{-1} \mathrm{~d}^{-1}\right) \\
(0-0.022)\end{array}$} \\
\hline & $(42.6 \%)$ & $(20.7 \%)$ & (13.4\%) \\
\hline \multicolumn{4}{|l|}{$\begin{array}{c}\text { Undecane } \\
\left(\mathrm{mg} \mathrm{kg}^{-1} \mathrm{~d}^{-1}\right) \\
(0-0.0014)\end{array}$} \\
\hline \multicolumn{4}{|l|}{$\begin{array}{c}\text { Phenol } \\
\left(\mathrm{mg} \mathrm{kg}^{-1} \mathrm{~d}^{-1}\right) \\
(0-0.0024)\end{array}$} \\
\hline \multicolumn{4}{|l|}{$\begin{array}{c}\text { Toluene } \\
\left(\mathrm{mg} \mathrm{kg}^{-1} \mathrm{~d}^{-1}\right) \\
(0-0.007)\end{array}$} \\
\hline$(0-0.0014)$ & $(41.1 \%)$ & $\overbrace{(18.1 \%)}$ & $(17.2 \%)$ \\
\hline
\end{tabular}

Figure 1. Variation of dependent variables as a function of normalized independent variables.

\section{RESULTS AND DISCUSSION}

Most of the common compounds emitted during MSW composting $^{30-32}$ were detected in this study, although some of previously identified compounds were not detected. This could be mainly attributed to the low levels of polymer components such as plastics, rubber, and other liquid oils present in the MSW used in this study. Among the compounds identified, seven VOCs were targeted for further statistical analysis due to their availability and high concentration in samples.

Relative Influence of the Selected Composting Parameters. To assess the relative influence of the selected independent variables (time, moisture, aeration, and $\mathrm{C} / \mathrm{N}$ ) on each dependent variable (compounds and temperature), the polynomial mathematical models were obtained (Table 4) by substituting the values of the measured independent variables for each dependent variable and applying a polynomial model analysis. Each value used to obtain the equations is the average of three measurements. The differences between the experimental values and those that were estimated using the previous equations never exceeded $10 \%$ of the former. Identifying the independent variables with the strongest/weakest influence on the dependent variables in equations was not easy because the former contains quadratic terms and the latter involves interactions between two independent variables.

Following the Díaz et al. ${ }^{33}$ method for analyzing the relative influence of the studied parameters, Figure 1 shows the plots of estimated values of each dependent variable (vertical axis) against estimated values of each independent one (horizontal axis), using normalized values from -1 to +1 for the independent variables. Figure 1 also shows (in brackets) the relative influence of each independent variable on the variation of each dependent variable.

As can be seen in Figure 1, the high impact of time on composting could minimize the relative impact of the other independent variables $(\mathrm{C} / \mathrm{N}$, aeration, and moisture). The relative influence of the independent variables on temperature and selected VOCs followed the order $\mathrm{C} / \mathrm{N}<$ moisture $<$ aeration. The results indicated that aeration had the strongest negative effect (higher values) on selected VOC emissions including the VOC that were affected. A general tendency of VOC emission to increase with the aeration and to diminish with the moisture and $\mathrm{C} / \mathrm{N}$ ratio was observed. These data agree with those found by Kuroda et al. ${ }^{34}$ in swine manure composting. In addition, these data are also corroborated by those described by Smyth and Rynk $^{35}$ in yard wastes composting where VOC emissions were inversely correlated with $\mathrm{C} / \mathrm{N}$ ratio.

The calculated values of the independent variables (response surface) from the equations (Table 3 ), giving the limonene, $\beta$-pinene, 2-butanone, undecane, phenol, toluene, dimethyl-disulfide, and dimethylsulfide emissions, were plotted for the three levels of the independent variable $\mathrm{C} / \mathrm{N}$ (Figures 2-6).

In a similar experiment with MSW-pine-trimming residues, both VOCs and $\mathrm{NH}_{3}{ }^{11}$ were measured. In that study, the relative influence of the independent variables on both VOCs and $\mathrm{NH}_{3}$ followed the order: moisture < aeration $<\mathrm{C} / \mathrm{N}$. Clearly, similar experiments provide slightly different results. This may be due to 
the great influence of the $\mathrm{NH}_{3}$ (which has not been evaluated in this study) on the exhaust gases ${ }^{10}$ and the high dependence of $\mathrm{NH}_{3}$ content on the temperature, oxygenation rate, and $\mathrm{C} / \mathrm{N}$ ratio. $^{36}$

Temperature Evolution. The three typical phases of composting (short initial mesophilic, thermophilic, and the second mesophilic) have been obtained in the models from data acquired during the experiment (Figure 2). Higher temperatures were observed for $60 \mathrm{C} / \mathrm{N}$ ratio reactors during the experiment with respect to 77 and $21 \mathrm{C} / \mathrm{N}$ ratio reactors. The $60 \mathrm{C} / \mathrm{N}$ ratio reactors reached a maximum temperature of $65^{\circ} \mathrm{C}$ after 13 days of composting. The $77 \mathrm{C} / \mathrm{N}$ and $21 \mathrm{C} / \mathrm{N}$ ratio reactors reached temperatures over $50^{\circ} \mathrm{C}$ in the same period. It is known that the course of decomposition of organic matter is affected by the presence of an optimum $\mathrm{C} / \mathrm{N}$ ratio ${ }^{37}$ due to biological activity, which depends on balanced nutrient supplies and values of $\mathrm{C} / \mathrm{N}$ ratio. In this study, for high $\mathrm{C} / \mathrm{N}$ (77) and low $\mathrm{C} / \mathrm{N}(21)$ ratio

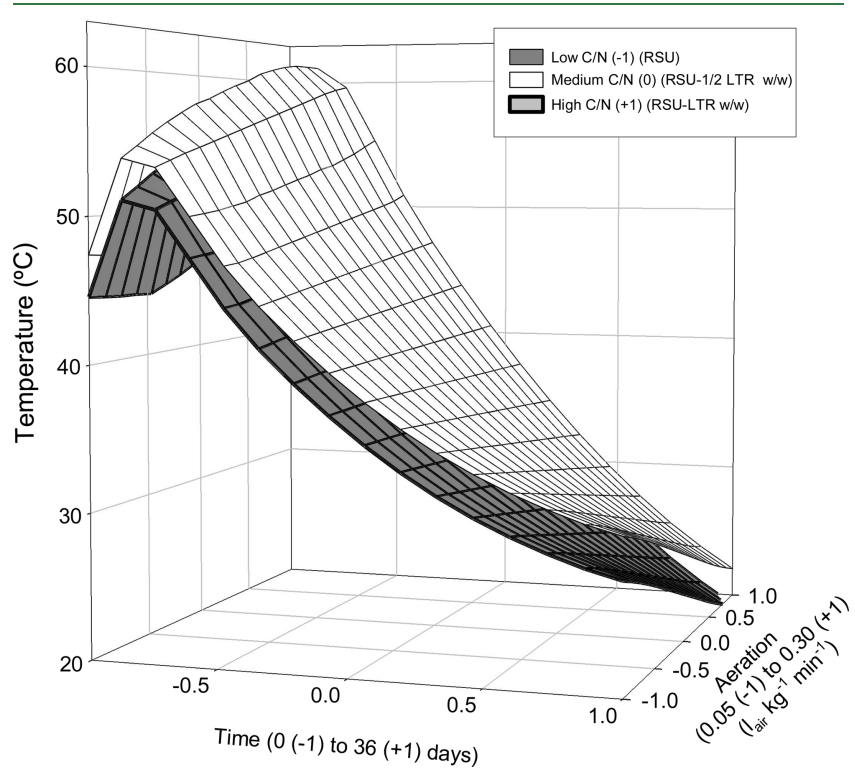

Figure 2. Temperature evolution as a function of time and aeration at three $\mathrm{C} / \mathrm{N}$ ratio levels. reactors, similar statistical trends have been found. In this instance, with respect to aeration, a positive effect (higher temperatures) during the thermophilic phase and a negative effect (lower temperatures) during the second mesophilic phase were observed regardless of $\mathrm{C} / \mathrm{N}$ ratio.

Evolution of Selected VOCs. Previous experiences have demonstrated the effectiveness of adding supplementary waste materials as bulking agents to improve the composting process and to minimize VOCs emissions from MSW. ${ }^{35}$ No significant statistical differences were observed among the different emitted VOCs in the selected experimental composting conditions.

Terpenes are the prevalent VOCs emitted in MSW composting facilities. ${ }^{26}$ Limonene (Figure $3 \mathrm{~A}$ ) and $\beta$-pinene (Figure 3B) are often released from wood chips and plant materials that are present or added to biowaste, and both were found to be at relatively high concentrations with respect to other VOCs. Moreover, high values for both compounds have been detected for high and medium $\mathrm{C} / \mathrm{N}$ ratios reactors as compared to low $\mathrm{C} / \mathrm{N}$ ratio reactors. As previously reported by other authors, these compounds were also determined to be released from raw material during the composting process. ${ }^{32}$ In addition, a progressive decrease in the emissions of these compounds during composting has been observed for all of the reactors. This decrease has been found to be larger for $\beta$-pinene than for limonene. In fact, after 15 days of composting, low $\beta$-pinene concentrations were detected. With respect to aeration, a positive effect has been observed (high VOCs concentration) on both compounds for all $\mathrm{C} / \mathrm{N}$ ratio reactors evaluated.

In general, the highest emissions are located in the early stages (thermophilic phase) of the processes and in the incoming materials as they are shredded. However, Eitzer ${ }^{26}$ found that the group of ketones reaches higher values in the mesoplilic phase. Among emitted ketones in composting, 2-butanone (Figure 4A) could be the most important component, ${ }^{38}$ and it has been classified as one of the most significant odor-causing VOCs in composting processes. ${ }^{5}$ Moreover, high undecane concentrations have been detected in MSW raw material. ${ }^{15}$ Komilis et al. ${ }^{4}$ found relatively high undecane concentrations in seeded mixed papers. With respect to 2-butanone and undecane (Figure 4B), a similar behavior to that shown for limonene has been found, and the initial values of 2-butanone and undecane
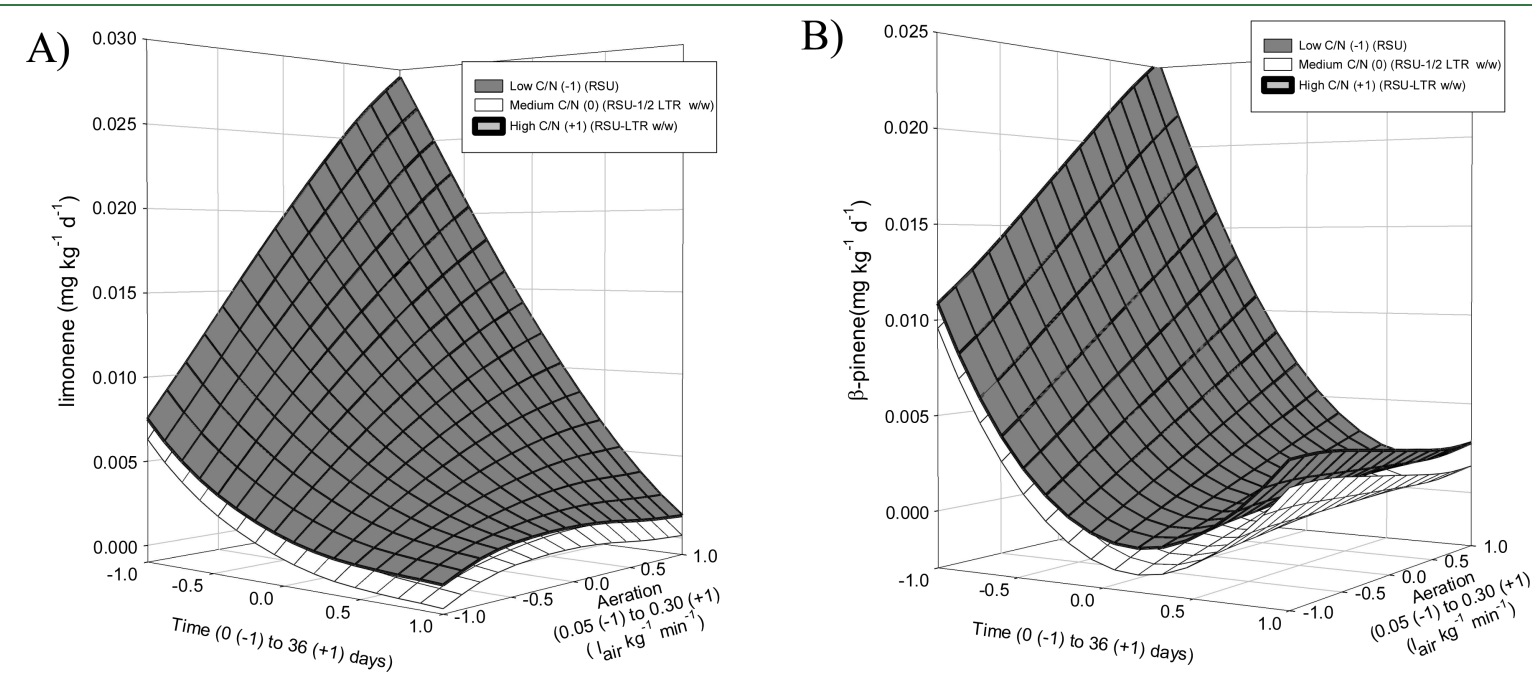

Figure 3. Limonene (A) and $\beta$-pinene (B) variation as a function of time and aeration at three $\mathrm{C} / \mathrm{N}$ ratio levels. 
A)

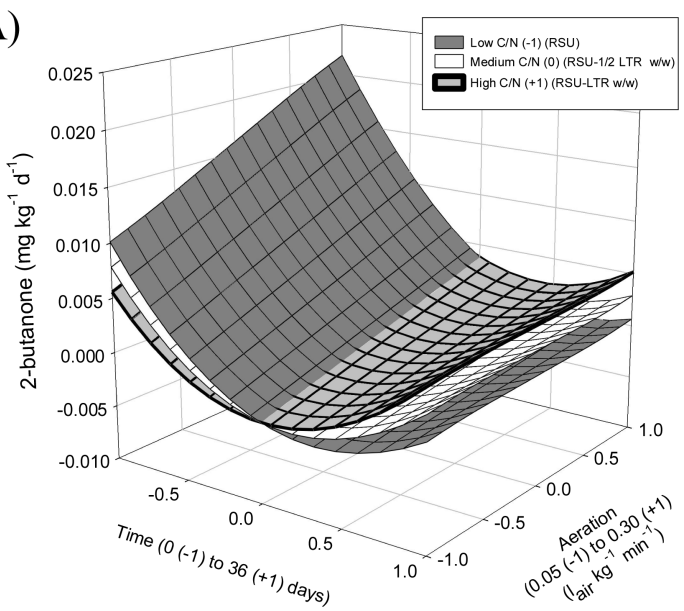

B)

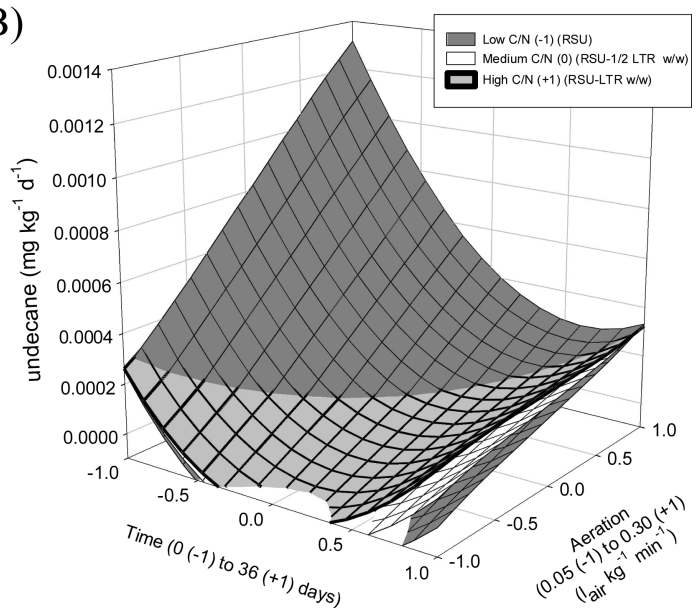

Figure 4. 2-Butanone (A) and undecane (B) variation as a function of time and aeration at three $\mathrm{C} / \mathrm{N}$ ratio levels.
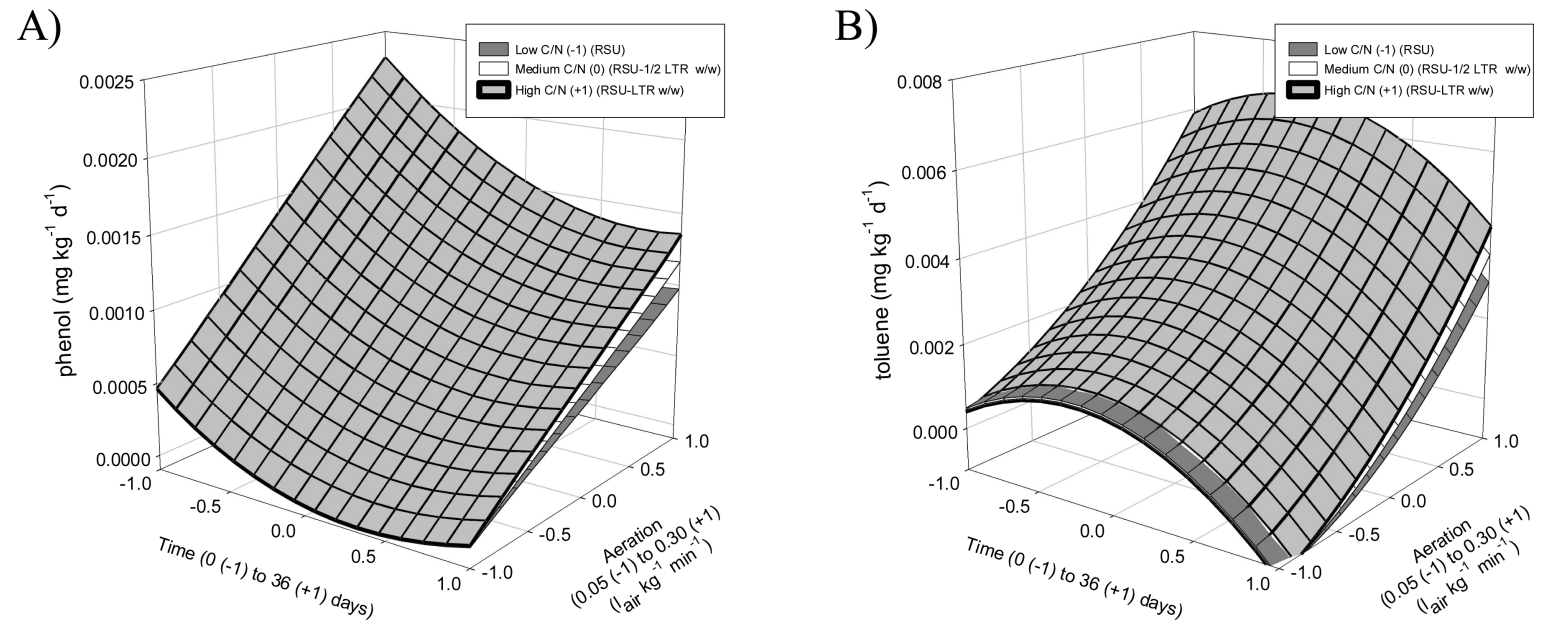

Figure 5. Phenol (A) and toluene (B) variation as a function of time and aeration at three $\mathrm{C} / \mathrm{N}$ ratio levels.

decreased during the first 15 days of composting (initial mesophilic and thermophilic stages) and reached undetectable levels at 15 days of composting. The initial values measured for both compounds were higher for low $\mathrm{C} / \mathrm{N}$ ratio reactors (only MSW) and lower for high $\mathrm{C} / \mathrm{N}$ ratio reactors. The decrease in 2-butanone and undecane emissions was more rapid for low $\mathrm{C} / \mathrm{N}$ ratio reactors. With respect to aeration, high values in 2-butanone and undecane were observed for high aeration reactors with respect to the medium and low aeration reactors in all of the $\mathrm{C} / \mathrm{N}$ ratios evaluated. Negligible values for both compounds were found at 36 days of composting in all tested conditions.

As occurred with other studied compounds, high values of phenol and toluene are detected in relatively high concentrations in composting processes. ${ }^{30}$ The evolution of emitted phenol and toluene under the selected composting conditions is shown in Figure 5A,B, respectively. In this regard, high concentrations of both compounds have been found at the initial stages of composting. As it occurred for the rest of the studied compounds, high values of phenol and toluene were detected under high aeration levels. In this case, the highest levels were detected for high $\mathrm{C} / \mathrm{N}$ ratio reactors for both compounds. After that, the data analysis demonstrated a decrease in the concentrations of emitted phenol under higher aeration levels, but low levels continued to be observed under high aeration levels. With respect to toluene, under thermophilic conditions, an increase has been identified. This could be due to the fact that toluene, a biomass degradation product, ${ }^{4}$ experienced an emission increase when more degradation occurred in the system; a progressive decrease was detected in the mesophilic phase. Similar to those found for phenol, higher values under higher aeration rates were observed.

The modeled evolution of emitted dimethyl disulfide under the selected composting conditions is shown in Figure 6. At the beginning of the process, an increase in dimetyl disulfide was detected, which could be attributed to the rise in temperature (Figure 2), indicating that microorganisms were degrading the organic natter from the waste with a corresponding decrease in oxygen. Under these conditions, higher values under medium aeration levels have been found. VOCs such as alcohols, carbonyl compounds, esters, and ethers are primarily released during the initial composting stages, while the volatile organic sulfur compounds (mainly dimethyl disulfide) are released during the thermophilic stage when oxygen becomes limited. ${ }^{36}$ In this study, after the thermophilic stage, a progressive decrease in dimethyl disulfide levels was observed and was negligible at the end of composting.

In conclusion, in general, a wide variety of volatiles are emitted from refuse waste material. The highest emissions of VOCs were 


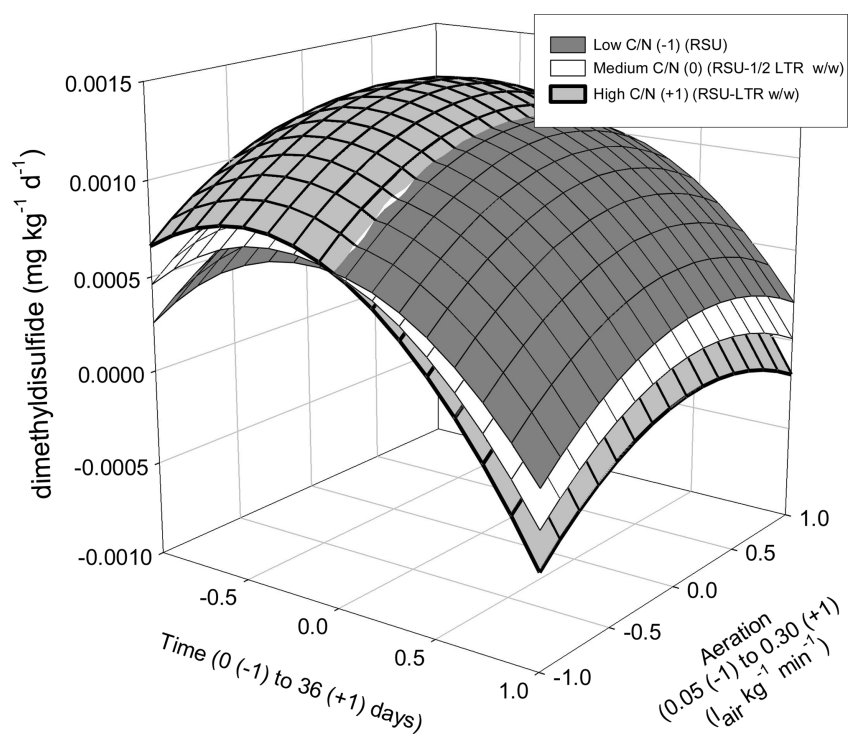

Figure 6. Dimethyldisufide variation as a function of time and aeration at three $\mathrm{C} / \mathrm{N}$ ratio levels.

in the early stages of the processes (initial and thermophilic phase). Overall, results of this study have shown the relative influence of the independent variables on temperature and VOCs followed the order aeration $>$ moisture $>\mathrm{C} / \mathrm{N}$. In this respect, the aeration rate had a strong negative effect (high values) on VOCs emissions (41-71\% on emitted VOCs variation). Moisture had a positive and negative effect depending on the selected compound. The $\mathrm{C} / \mathrm{N}$ ratio has a positive effect (low values) on VOC emissions in almost all of the evaluated compounds with the exception of undecane and 2-butanone. Consequently, to minimize emitted VOC and odors during MSW composting, low aeration (remain aerobic; $0.05 \mathrm{~L}_{\text {air }} \mathrm{kg}^{-1} \mathrm{~min}^{-1}$ ), high $\mathrm{C} / \mathrm{N}$ ratio $(>50)$, and medium moisture (55\%) may be a suitable selection.

\section{AUTHOR INFORMATION}

\section{Corresponding Author}

*Tel: +34 959219990. Fax: +34 959219983. E-mail: dblanco@ uhu.es.

\section{Funding Sources}

We acknowledge financial support from the CICYT (Science and Technology Inter Ministerial Commission, Spanish Government)FEDER, project number CTM2007-62117/TECNO.

\section{ACKNOWLEDGMENT}

Special thanks to Juan Revilla (SADECO) for his collaboration.

\section{REFERENCES}

(1) Walker, L.; Charles, W.; Cord-Ruwisch, R. Comparison of static, in-vessel composting of MSW with thermophilic anaerobic digestion and combinations of the two processes. Bioresour. Technol. 2009, 10, 3799-3807.

(2) Domingo, J. L.; Nadal, M. Domestic waste composting facilities: A review of human health risks. Environ. Int. 2009, 35, 382-389.

(3) NSWMA (National Solid Wastes Management Association). Managing Solid Waste Facilities to Prevent Odor, 2008; http://www. cornerstoneeg.com/Managing Solid Waste Facilities.pdf.
(4) Komilis, D. P.; Ham, R.; Park, J. K. Emission of volatile organic compounds during composting of municipal solid wastes. Water Res. 2004, 38, 1707-1714.

(5) Tolvanen, O.; Nykänen, J.; Nivukoski, U.; Himanen, M.; Veijanen, A.; Hänninen, K. Occupational hygiene in a Finnish drum composting plant. Waste Manage. 2005, 25, 427-433.

(6) Sironi, S.; Capelli, L.; Céntola, P.; Del Rosso, R.; Grande, M. Continuous monitoring of odours from a composting plant using electronic noses. Waste Manage. 2007, 27, 389-397.

(7) Kissel, J. C.; Henry, C. L.; Harrison, R. B. Potential emissions of volatile and odorous organic compounds from municipal solid waste composting facilities. Biomass Bioenergy 1992, 3, 181-194.

(8) Mao, I. F.; Tsai, C. J.; Shen, S. H.; Lin, T. F.; Chen, W. K.; Chen, M. L. Critical components of odors in evaluating the performance of food waste composting plants. Sci. Total Environ. 2006, 370, 323-329.

(9) Tsai, C. J.; Chen, M. L.; Ye, A..D.; Chou, M. S.; Shen, S. H.; Mao, I. F. The relationship of odor concentration and the critical components emitted from food waste composting plants. Atmos. Environ. 2008, $42,8246-8251$.

(10) Cadena, E.; Colón, J.; Sánchez, A.; Font, X.; Artola, A. A methodology to determine gaseous emissions in a composting plant. Waste Manage. 2009, 29, 2799-2807.

(11) Delgado-Rodríguez, M.; Ruiz-Montoya, M.; Giraldez, I.; Cabeza, I. O.; López, R; Díaz, M. J. Effect of control parameters on emitted volatile compounds in municipal solid waste and pine trimmings composting. J. Environ. Sci. Health, Part A 2010, 45, 855-862.

(12) Commission of the European Communities. Commission decision of 3 November 2006 establishing revised ecological criteria and the related assessment and verification requirements for the award of the Community eco-label to soil improvers. Off. J. Eur. Union L. 2006, $325,28-34$.

(13) Bremnen, J. M. Nitrogen-Total. In Methods of Soil Analysis; Sparks, D. L., Ed.; SSSA: Madison, WI, 1996; Vol. 3, pp 1085-1121.

(14) Pierucci, P.; Porazzi, E.; Pardo Martinez, M.; Adani, F.; Carati, C.; Rubino, F. M.; Colombi, A.; Calcaterra, E.; Benfenati, E. Volatile organic compounds produced during the aerobic biological processing of municipal solid waste in a pilot plant. Chemosphere 2005, 59, 423-430.

(15) Cai, L.; Koziel, J. A.; Lo, Y. C.; Steven, J.; Hoff, S. J. Characterization of volatile organic compounds and odorants associated with swine barn particulate matter using solid-phase microextraction and gas chromatography - mass spectrometry-olfactometry. J. Chromatogr., A 2006, 1102, 60-72.

(16) Hachem, C.; Fazio, P.; Rao, J.; Bartlett, K.; Chaubey, Y. P. Identification and Transport Investigation of Microbial Volatile Organic Compounds in Full Scale Stud Cavities. Build. Environ. 2009, 44, 1691-1698.

(17) Akhnazarova, S.; Kafarov, V. In Experiment Optimization in Chemistry and Chemical Engineering; Mir Publisher: Moscow, 1982.

(18) Madejon, E.; Díaz, M. J.; Lopez, R.; Cabrera, F. New approaches to establish optimum moisture content for compostable materials. Bioresour. Technol. 2002, 85, 73-78.

(19) Kulcu, R.; Yaldiz, O. Determination of aeration rate and kinetics of composting some agricultural wastes. Bioresour. Technol. 2004, 93, 49-57.

(20) Haug, R. T. In The Practical Handbook of Compost Engineering; Lewis Publishers: Boca Raton, FL, 1993.

(21) Pagans, E.; Barrena, R.; Font, X.; Sánchez, A. Ammonia emissions from the composting of different organic wastes. Dependency on process temperature. Chemosphere 2006a, 62, 1534-1542.

(22) Saidi, N.; Chérif, M.; Jedidi, N.; Mahrouk, M.; Fumio, M.; Boudabous, A.; Hassen, A. Evolution of Biochemical Parameters during Composting of Various Wastes Compost. Am. J. Environ. Sci. 2008, 4, 332-341.

(23) Derikx, P.J. L.; Simons, F. H. M.; Op den Camp, H.J. M.; Van der Drift, C.; Van Griensven, L. J. L. D.; Vogels, G. D. Evolution of Volatile Sulfur Compounds during Laboratory-Scale Incubations and Indoor Preparation of Compost Used as a Substrate in Mushroom Cultivation. Appl. Environ. Microbiol. 1991, 57, 563-567. 
(24) Müller, T.; Thissen, R.; Braun, S.; Dott, W.; Fischer, G. (M)VOC and composting facilities. Part 1: (M)VOC emissions from municipal biowaste and plant refuse. Environ. Sci. Pollut. Res. 2004, 11, 91-7.

(25) Schlegelmilch, M.; Streese, J.; Biedermann, W.; Herold, T.; Stegmann, R. Odour control at biowaste composting facilities. Waste Manage. 2005, 25, 917-927.

(26) Eitzer, B. D. Emissions of volatile organic chemicals from municipal solid waste composting facilities. Environ. Sci. Technol. 1995, 29, 896-902.

(27) Liu, Q.; Li, M.; Chen, R.; Li, Z.; Qian, G.; An, T.; Fu, J.; Sheng, $\mathrm{G}$. Biofiltration treatment of odors from municipal solid waste treatment plants. Waste Manage. 2009, 29, 2051-58.

(28) Hamacher, T.; Niess, J.; Schulze Lammers, P.; Diekmann, B.; Boeker, P. Online measurement of odorous gases close to the odour threshold with a QMB sensor system with an integrated preconcentration unit. Sens. Actuators, B 2003, 95, 39-45.

(29) Staley, B. F.; Xu, F.; Cowie, S. J.; Barlaz, M. A. Hater GR.. Release of trace organic compounds during the decomposition of municipal solid waste components. Environ. Sci. Technol. 2006, 40, 5984-5991.

(30) Bruno, P.; Caselli, M.; De Gennaro, G.; Solito, M.; Tutino, M. Monitoring of odor compounds produced by solid waste treatment plants with diffusive samplers. Waste Manage. 2007, 27, 539-544.

(31) Chiriac, R.; Carre, J.; Perrodin, Y.; Fine, L.; Letoffe, J. M. Characterisation of VOCs emitted by open cells receiving municipal solid waste. J. Hazard. Mater. 2007, 149, 249-63.

(32) Defoer, N.; De Bo, I.; Van Langenhove, H.; Dewulf, J.; Van Elst, T. Gas chromatography-mass spectrometry as a tool for estimating odour concentrations of biofilter effluents at aerobic composting and rendering plants. J. Chromatogr., A 2002, 970, 259-273.

(33) Díaz, M. J.; Alfaro, A.; García, M. M.; Eugenio, M. E.; Ariza, J.; López, F. Ethanol pulping from tagasaste (Chamaecytisus proliferus L.F. ssp. palmensis). A new promising source for cellulose pulp. Ind. Eng. Chem. Res. 2004, 43, 1875-1881.

(34) Kuroda, K.; Osada, T.; Yonaga, M.; Kanematu, A.; Nitta, T.; Mouri, S.; Kojima, T. Emissions of malodorous compounds and greenhouse gases from composting swine feces. Bioresour. Technol. 1996, $56,265-271$.

(35) Smyth, B.; Rynk, R. Can Composting BMPs Reduce Air Emissions?. BioCycle 2004, 45, 46-50.

(36) Pagans, E.; Font, X.; Sanchez, A. Emission of Volatile Organic Compounds from Composting of Different Solid Wastes: Abatement by Biofiltration. J. Hazard. Mater. 2006b, 131, 179-186.

(37) Huang, G. F.; Wong, J. W.; Wu, Q. T.; Nagar, B. B. Effect of C/N on composting of pig manure with sawdust. Waste Manage. 2004, 24, $805-813$.

(38) Fricke, K.; Santen, H.; Wallmann, R. Comparison of selected aerobic and anaerobic procedures for MSW treatment. Waste Manage. 2005, 25, 799-810. 